SUPPORTING INFORMATION for Covalently Attached Monolayers on Crystalline Hydrogen-Terminated Silicon: Extremely Mild Attachment by Visible Light - Sun, Q.-Y., et al.

\title{
Angle-dependent IRRAS.
}

Angle-dependent IRRA spectra on a Si(111) sample modified with tetradecyne (447 $\mathrm{nm}, 15 \mathrm{~h}$ ) showing that good spectra were obtained for angles between $\sim 60^{\circ}$ and $\sim 70^{\circ}$.

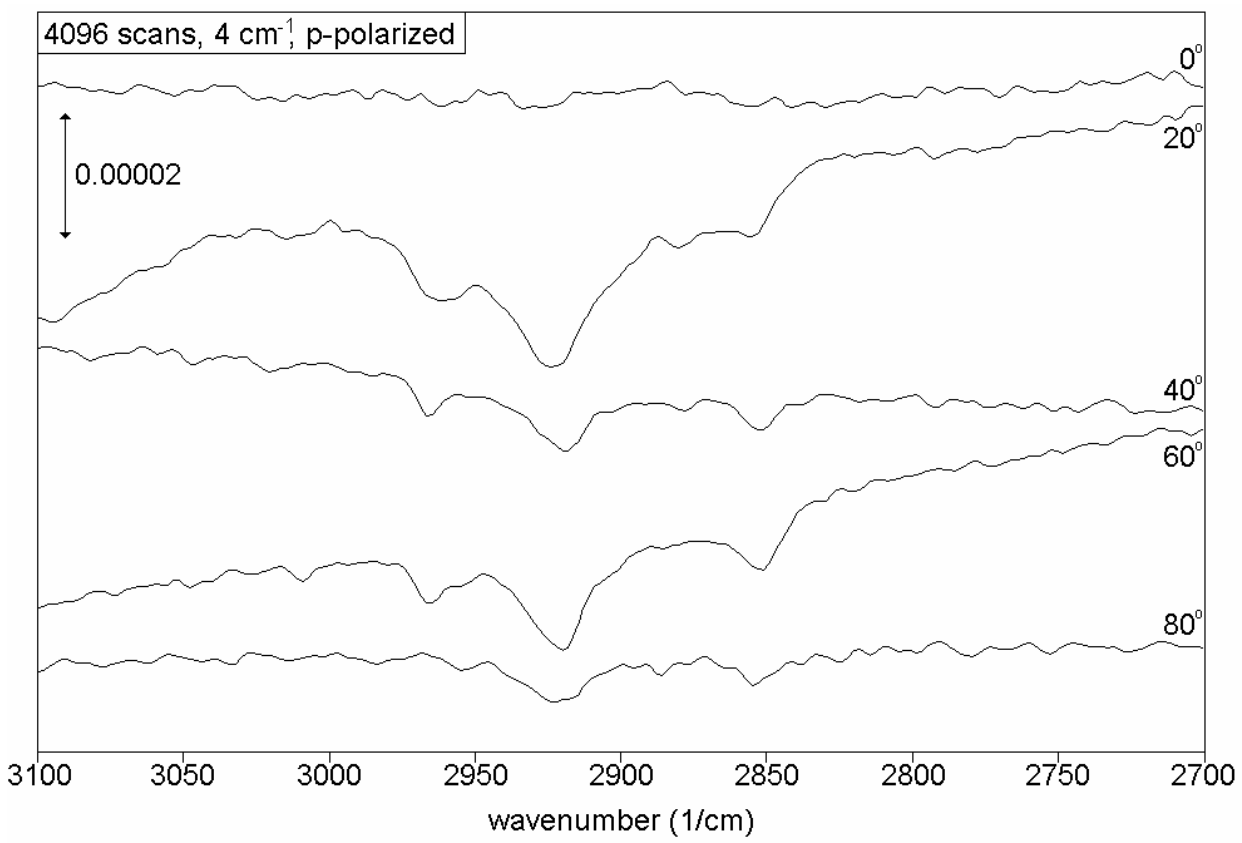




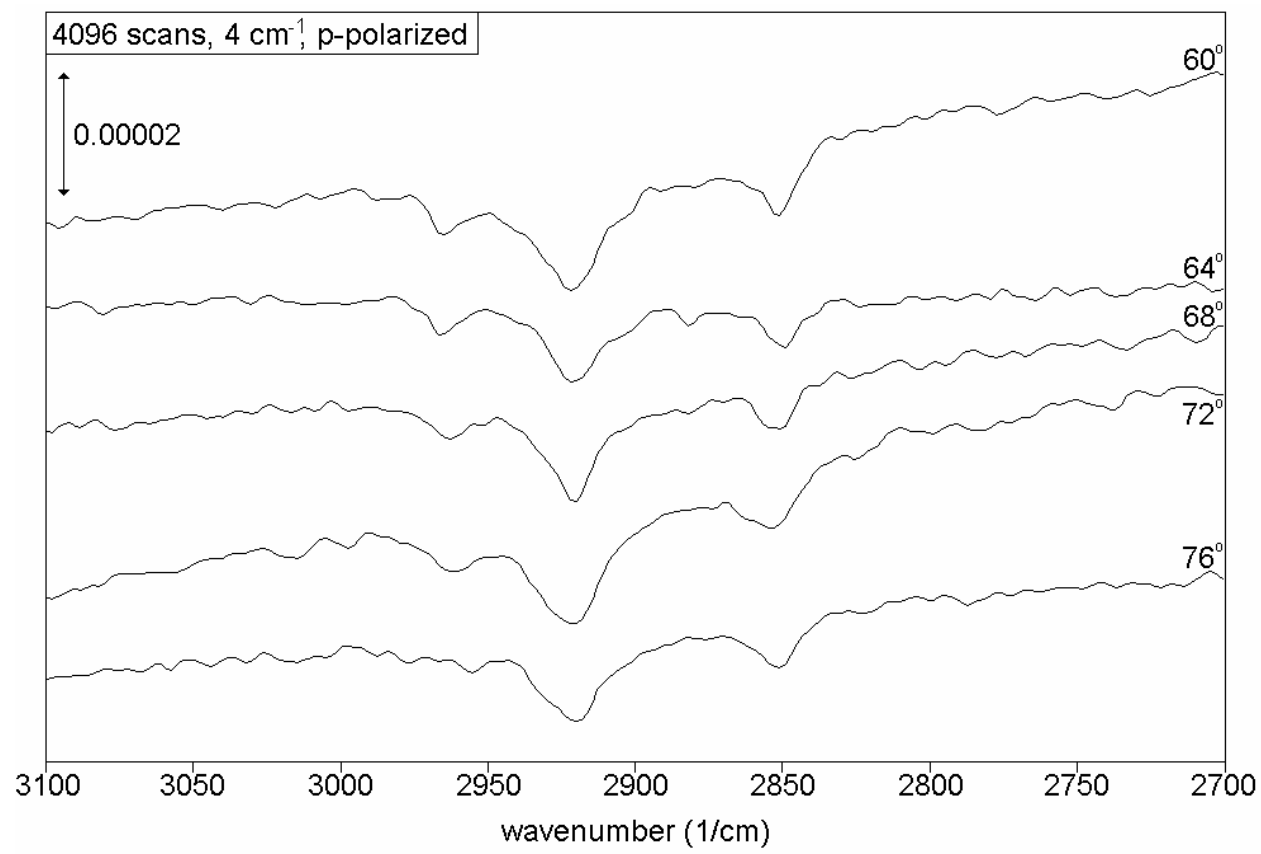


B) Synthesis of 10-Undecenoic Acid 2,2,2-Trifluoroethanol Ester

\section{General Information}

Benzene (Janssen Chimica, 99\%) was dried over sodium wires and pyridine (Merck, 99\%) was dried over $\mathrm{KOH}$. 2,2,2-Trifluoroethanol (Aldrich, 99+\%) and 10-undecenoyl chloride (Fluka, $\geq 97 \%$ ) were used as received. See paper for information about the TLC and column chromatography.

\section{0-Undecenoic Acid 2,2,2-Trifluoroethanol Ester (compound II)}

10-Undecylenic chloride ( $20.00 \mathrm{~g}, 98.7 \mathrm{mmol}$ ) in $20 \mathrm{~mL}$ of benzene was added to a stirring solution of 2,2,2-trifluoroethanol $(10 \mathrm{~mL}, 137 \mathrm{mmol})$ in pyridine $(10 \mathrm{~mL})$ under a nitrogen atmosphere at $0{ }^{\circ} \mathrm{C}$ over a period of $3 \mathrm{~h}$. The reaction mixture was allowed to warm to room temperature, left over night, and water $(75 \mathrm{~mL})$ and ether $(100 \mathrm{~mL})$ were added. The layers were separated and the aqueous layer was extracted with ether until TLC showed the absent of product in the organic layer. The combined organic layers were washed with $0.5 \mathrm{M} \mathrm{HCl}$ until pyridine was removed, washed with saturated $\mathrm{NaHCO}_{3}(100 \mathrm{~mL})$, water $(100 \mathrm{~mL})$, and brine $(100 \mathrm{~mL})$. The organic layer was dried over $\mathrm{Na}_{2} \mathrm{SO}_{4}$. After filtration, the solvent was removed under reduced pressure at $40{ }^{\circ} \mathrm{C}$, yielding $25.01 \mathrm{~g}$ of crude product. Purification by column chromatography $\left(\mathrm{PE} 40 / 60: \mathrm{CH}_{2} \mathrm{Cl}_{2}=2: 1\right)$ yielded $24.24 \mathrm{~g}$ (91.0 mmol, 92\%) of the title compound: TLC $R_{f}\left(\mathrm{PE} 40 / 60: \mathrm{CH}_{2} \mathrm{Cl}_{2}=2: 1\right)$ $=0.39 .{ }^{1} \mathrm{H}$ NMR $\left(200 \mathrm{MHz}, \mathrm{CDCl}_{3}\right) \delta=5.89-5.69(\mathrm{~m}, 1 \mathrm{H}), 5.01-4.89(\mathrm{~m}, 2 \mathrm{H})$, 4.51-4.38 (q, $J=\sim 8.5 \mathrm{~Hz}, 2 \mathrm{H}$ ), 2.39 (t, $J=\sim 7.5 \mathrm{~Hz}, 2 \mathrm{H}$ ), 2.0-1.9 (q, $J=6.8 \mathrm{~Hz}$, $2 \mathrm{H}), 1.7-1.6(\mathrm{~m}, 2 \mathrm{H}), 1.28$ (bs, $10 \mathrm{H}) ;{ }^{13} \mathrm{C} \mathrm{NMR}\left(50 \mathrm{MHz}, \mathrm{CDCl}_{3}\right) \delta=173.09$, 140.09, 123.96 (q, $J=275 \mathrm{~Hz}$ ), 115.09, 61.04 (q, $J=36 \mathrm{~Hz}$ ), 34.73, 34.56, 30.18, 30.06, 29.96, 29.88, 29.82, 25.62; IR (film between NaCl windows, $\mathrm{cm}^{-1}$ ): 3080 (w, vinyl-H), 2929 (m-s, C-H), 2857 (m, C-H), 1762 (s, C=O), 1641 (w-m, C=C), 1283-1170 (s-vs, C-O). 